\begin{tabular}{llll}
$K$ & $R$ & $i$ & $z$ \\
\hline
\end{tabular}

Kriz Dergisi 10 (2): 49-60

\title{
IMATION OF AMOK AND AMOK-SUICIDE
}

\author{
A. Schmidtke*, S. Schaller", I. Mứllert*t
}

\section{ABSTRACT}

In the scientific literature there is no doubt that imitation effects on aggression and suicide exist. The reporting or portrayal of aggressive or suicidal behaviour might be influential in the short and long term. Previous data suggest that also amok behaviour might be imitated. An analysis of 132 reports of amok events for the time period 01. 01. $1993-30.06 .2000$ in two major German newspapers showed that the majority of amok events are not distributed by chance over time. Most amok events follow an other event in a period of time which is within the

- Prof. Dr., Department of Clinical Psychology, Department of Psychiatry, University of Würzburg, Germany.

** Klinik Psikolog, Otto-Selz-Institute for Psychology and Education, University of Mannheim, Germany.

*** Klinik Psikolog, Department of Clinical Psychology, Department of Psychiatry, University of Würzburg \& D. Lester, Richard Stockton College, Pormona, New Jersey. frame given by many studies of imitation: 10 days in Phillips (1974) studies, 18 days in the study by Schmidtke \& Häfner (1988). This uneven distribution speaks for a possible trigger effect. There are also examples of a strong similarity between the events with regard to person variables and the "modus operandi" of the acts. Therefore, it may be dangerous to report about amok events in a sensational way. The reporting may trigger the same attitude and behaviour in persons who found themselves in a similar state of mood. That it would be possible to use the media also for preventing such acts is clearly shown by some studies on media effects on suicidal behaviour.

Key Words: Imitation, modelling, amok, suicide

\section{INTRODUCTION}

Today the majority of studies show that imitation effects on aggression and suicide exist (Berkowitz \& Macaulay, 1971; Cantor \& Sheehan, 1996; Velting \& Gould, 1997; 


\begin{tabular}{llll}
$K$ & $R$ & $\mathrm{I}$ & $\mathrm{Z}$ \\
\hline
\end{tabular}

Schmidtke \& Schaller, 2000, Hawton et al., 2001; Schmidtke, Schaller \& Wassermann, 2001).

Hypotheses that may explain divergent findings emphasise that it seems likely that the imitation effects depend on a range of variables (Schmidtke \& Schaller, 2000).

- Kind of medja

The effects clearly depend on the kind of media. Today one can distinguish the media according to the kind of presentation: print media (newspapers, books, magazines), music, theatre, movies, TV or new electronic medias (Internet; Fekete \& Schmidtke, 1966; Schmidtke \& Schaller, 2000).

- Kind of behaviour

Also the behaviour portrayed can be differentiated, for example whether the behaviour shown is real or fictional and whether acts or thoughts of an individual person or general theories about aggressive and suicidal behaviour are presented. In general with regard to suicidal behaviour it is assumed that the facts support more an imitation of real behaviour as of fictional behaviour (Schmidtke \& Schaller, 2000; Hawton et al., 2001).

\section{- Dosage effect}

The effect depends also on the "dosage" of reporting. As early as in the studies of Phillips (1974) and Phillips \& Hensley (1984) it was already shown that the imitation effects clearly depend on the dosage of reporting and the size of the audience, e.g. the number of possible imitators: the more publicity, the higher the imitation effect. Also newer studies show a clear association between the number of presentations (Schmidtke \& Häfner, 1988), the size of distribution (Etzersdorfer, 2001) and the size of the imitation effect.

-Size of audience or number of possible imitators

The effect of the size of the audience was also clearly shown in some studies: The increase of suicides depends on the size of audience (Motto, 1970; Schmidtke \& Häfner, 1988, Etzersdorfer, 2001).

- Similarities between model and possible imitator

The effect of imitation also clearly depends on similarities between the model and the potential imitators.

This effect was shown for aggression in the studies by Phillips and co-workers: After boxing contests the aggression depended on whether a white person or an Afro-American won the fight (Phillips, 1983). For suicide this evidence was proven in the studies by Phillips and Schmidtke \& Häfner (1988): white actors were more imitated by whites, young male suicides more by young males. Stack (1996) investigated imitation effects in Japan. The increase in the occurrence of suicjde tollowing exposure to portrayal of suicide in newspapers was similar in magnitude to that reported in the context of American culture; however the imitation effect was restricted to Japanese victims. The methods were copied in the study by Gould and Shaffer (1986)in one case and in the studies by Schmidtke \& Häfner (1988),"railway suicide" and in the study by Etzersdorfer (2001; "shooting").

- Short and long term influence

A further hypothesis for the different findings is that reporting or portrayal of suicidal 
behaviour and the presentation of fictional suicide models might influence a population's suicidal behaviour in the short and long term. Impulsive imitators can already be in a state of mood predisposing them to such a behaviour and may be triggered to impulsive behaviour, an other group may be influenced by the media in the long run to the view that this form of behaviour is "a common and understandable way" of problem solving (Häfner \& Schmidtke, 1986; Schmidtke \& Schaller, 2000).

In the context of imitation of suicidal behaviour also the influence of murder-suicides, mass murders or amok events have been discussed. Murder suicides are killing acts followed by the súicide of the persons who killed. Mass murders are cases of the killing of several people, not necessarily in a short period of time.

Using monthly data of mass murders and murder-suicides for the period 1968-1980, Stack showed in 1989 that publicized mass murder/suicides were significantly associated with increases in the suicide rate. In contrast, the homicide rate was not affected by publicized mass-murder/suicides. All in all, publicized mass murders were unrelated to lethal aggression. However, there was one exception: publicized gangland mass murders were also associated with increases in suicide.

The word Amok stems from the malaysian AMOK (Oxford English Dictionary, 1989, p. 407). There are many derivates of the word, like for example amokdriver, amokrunner etc. Amok is a culturally specific syndrome, which has been known for centuries in the Malayan culture. During the centuries the definition had under gone major changes. It was normally characterized through typical phases: an early stage of gloomy brooding, the amok running itself with wild often deadly attacks against other people who were often only by chance present and a later stage of sleeping or stupor with following amnesia. Pseudo-amok is a weaker form of this behaviour, which goes together with mock attacks against persons in the vicinity. Here the inhibitions about killing are not overcome.

In the US also the definition of rampage killer is used. A rampage killer is defined as a person who kills where possible without motive as many people he or she can.

Today in psychiatric classification systems AMOK can be found under different syndromes. In ICD 10 Amok itself is not mentioned. In DSM IV amok is described among the culturally bound syndromes or among the dissociative disorders.

In the literature amok persons are normally desribed as males, young or middle-aged, killing other people in a state of rage without visible motives (Adler et al., 1993; Adler, 2000, 2001).

Many authors mention psychiatric symptoms of the amok runners (Adler, 2001). Endogenous and exogenous psychoses were for example already assumed by Kraepelin (1904), Baechler (1981) and Ellis (1983). Arboleda-Florez and coworkers (1985) hypothesized mostly schizoid and paranoid disorders of young males. In contrast, Murphy (1982) saw more narcissistic personality disorders. Schmidt and co-workers assumed emotional instability with passive-aggressive and antisocial traits. Many others see also disorders of impulse control ("explosible" disor- 
ders; e.g. Bach-Y-Rita, 1971, Maletzky, 1973 and others). However, it remains questionable whether the latter diagnosis is a kind of "contaminated diagnosis" -known for example also in suicidology, that means the act is only described in other words.

Today, amok incidents have normally a great media coverage as well as a coverage in electronic media (e.g. Internet) in all parts of the world. Therefore, it is not unreasonable to test the hypothesis whether or not amok events themselves can be imitated as a result of media reports. Cantor and Sheehan (1996) were the first authors to look more closely into this imitation hypothesis. They compared the modus operandi of two amok killers and found astonishing similarities. On August 9th, 1987, in a suburb of Melbourne Australia a gunman shot dead six persons seemingly unknown to him and injured at least 18 others. Ten days later in a town in England, another gunman similarly killed 14 people, injured 16 others and committed suicide. Analyses of the press reports indicated major similarities of features associated with the two set of events.

Based on the findings of the previous imitation studies for suicidal behaviour and the study of Cantor and Sheehan (1996), it seems worth testing the hypothesis whether reports of amok events can trigger other amok incidents.

\section{METHOD}

\section{Material}

As material two main German newspapers distributed nationwide were used: The Frankfurter Allgemeine Zeitung (FAZ), which is a national quality newspaper, and one of the most respected newspapers, and the Bild-
Zeitung, a tabloid paper with the greatest nationwide distribution.

All press reports about events with persons trying to kill other persons without any - at first glance -logical reason were identified. Only those events in which the word "Amok" was used by the journalists themselves were used for the statistical analyses. General reports about AMOK were excluded. For the description of the AMOK events only the reports about the behaviour in the newspapers were taken, since only those descriptions could trigger imitations, not the later court reports or psychiatric files.

Data for the period ist of January 1993 till 30 th of June 2000 were available on electronic files for both journals.

132 amok cases were classified.

\section{Statistical Analyses}

To evaluate the statistical significances, $\mathrm{CH}$-Squares and Fisher exact probability tests as well as runs tests were used. The runs tests can be used as a test of serial independency or the randomness of the temporal occurrence or sequence of events (Siegel, 1956). We assumed a time independency of the amok events. A run is a sequence of similar events or non-events. The more runs the less probable is an imitation effect.

\section{RESULTS}

\section{Quantitative Analyses}

In the Frankfurter Algemeine Zeitung (FAZ) for the period 01. 01. 1993 - end of June 2000132 amok events were reported. All events for which in the report also the word amok was used, which were, however, in reality not amok events, were excluded. 
In the Bild-Zeitung, the tabloid paper, for the same time period more than 300 amok incidents were reported. In this joumal the word amok was much more used in context of the reporting of an event, which according to the definition had nothing to do with real amok events.

There exists a list from the New York Times, which we received with the help of the fourth author of so called "rampage killers". From 1993 -end of 199962 rampage killer cases with 64 persons were reported in this list.

The 64 persons in the US list were mostly males( 60 males, 4 fermales), their mean age was 34 years and their mean killing rate was 3,1 persons.

The German FAZ cases are all males, their mean age is 35 years, their mean killing rate is 4 persons.

Since the US list and the German list did not tally very well -the reason being that in the US list mostly only Americans were listed and not all cases were "amok" cases -for the first analysis only the FAZ data were used. The reason for this was the hypothesis that when the occurrence of an amok event was reported in the FAZ it was with a high probability also reported in other newspapers and various television channels. Using this data we tested in a more conservative way.

Over the period of time investigated, the results show that despite the great press coverage the number of amok events significantly decreased over time (see figure 1).

49 of the events took place in Europe, 50 in the US and the Americas and 33 in other countries of the world.
In 130 cases the further history of the amok runner was reported. In $28 \%$ of these amok cases the amok event was followed by the suicide of the amok runner.

The mean time period between the amok events was 20,6 days, with a standard deviation of 20,93 days, the range being 0 -day-102 days. One can expect on average one amok event every third week. Figure 2 shows the distribution of the events. This distribution supports at first glance the hypothesis that amok events may trigger other amok events. If one divides the time period in four periods, $0-10$ th day, 11-20th day, 21-30th day and over 30 days $44 \%$ percent of all events followed in the first 10 days after an amok event, that means closer than one would expect by chance. 16,0 percent in the second 20 days. This gives a Chi-Square of $30,37(p<.001)$. If one divides the period in 5 segments $(1-10,11-20,21-30,31-40$, and 41 and more days), the Chi-square is 49,88 $(p<.001)$.

\section{Qualitative Anolyses}

\section{Modus operandi}

in general the amok runners were all males, mainly younger males. The mean age was 35 years. None of the runners was female. Surprisingly high is the rate of people with a connection to professions where guns are used or at least familiar: the military $(28 \%)$ and the police $(7 \%)$. These percentages are much higher than the rate of these professions in the population and than one would expect by chance. For some time periods the profession or peer group of the person was similar (clerk, soldier, student).

The circumstances of the act, in most cases not explicitly given in the publication, do 

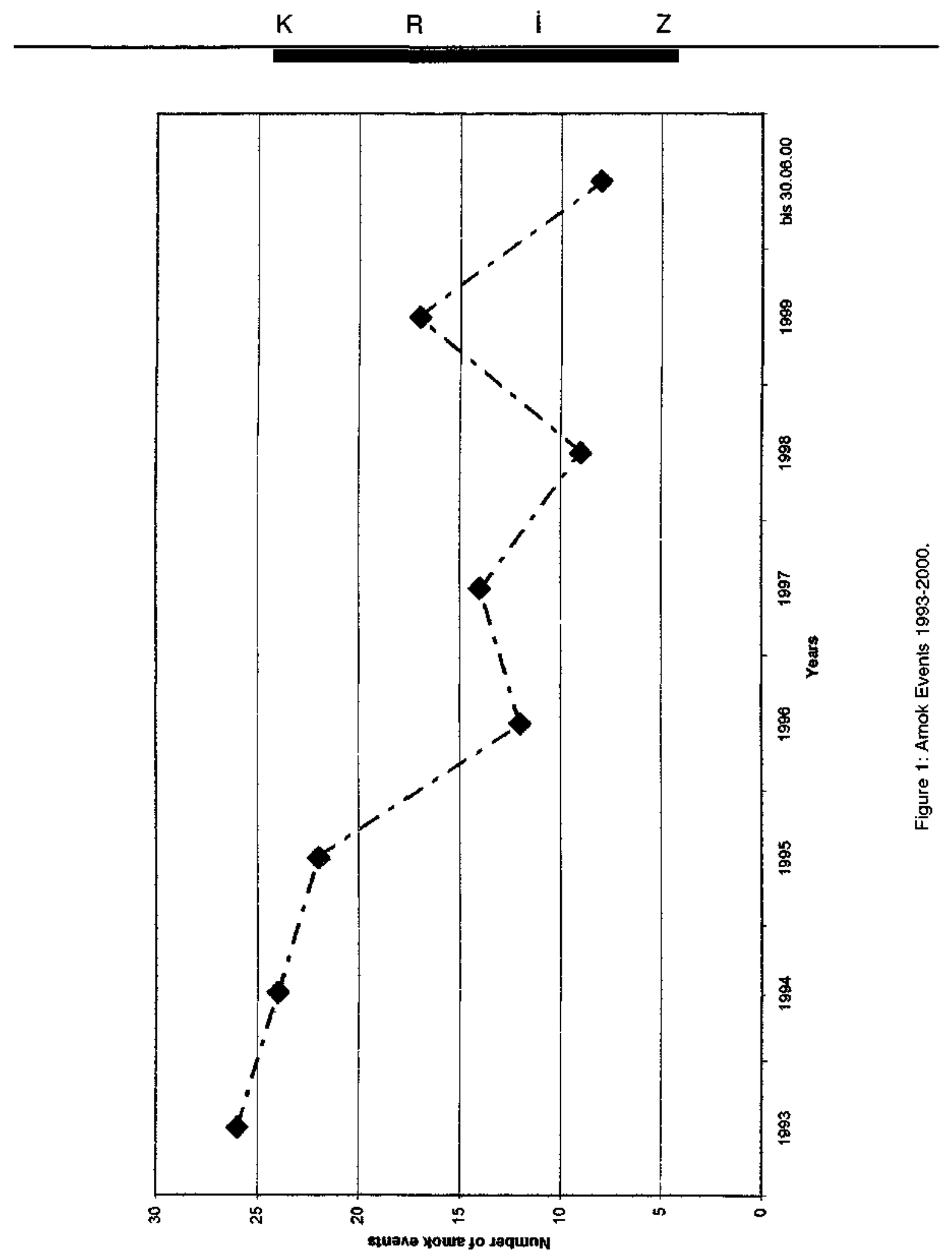
$\begin{array}{llll}K & \text { R } & \text { I } & \text { Z }\end{array}$

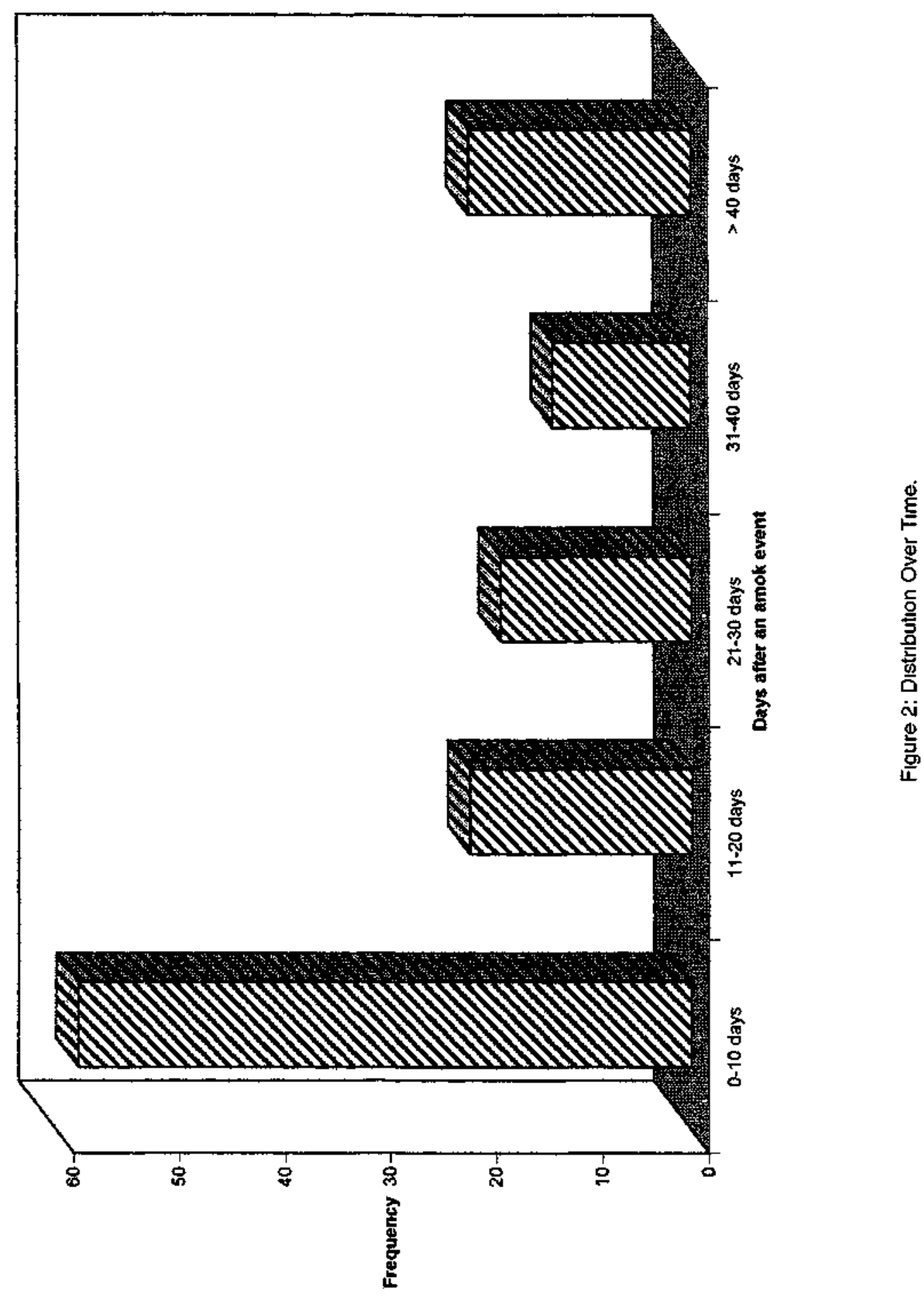


not reflect at first glance a high degree of similarity. However in some cases the similarities were overwhelming. The most similar cases were the following:

Australian (Clifton Hill) and English (Hungerford) case (a case outside the time span covered): Time difference 10 days; in both cases young lonely males, the one a member of gun clubs, the other owner of a gun shop, similar dress: army clothing or combat dress, similar kind of weapons: automatic weapons; and the act itself was described in both cases as Rambo like: the targeting was in both cases random, they shot at pedestrians and vehicles.

23th of May 1998: AUS student killed 4 people. Also camouflage clothing and automatic weapons were used, in the same week some shootings in schools.

08th of May 1993 in Michigan: a post office clerk shot at colleagues, the reason being that a free post was given to a female colleague, 3 deaths. Same day in California: a post office clerk shot at several colleagues, he had been dismissed and tried to kill his superior.

25th of September 1995: A 16-year old French male youngster killed his family with a hammer or a base-ball bat, the next morning he shot at passers-by on the main square of the city. 11 days later: in Munich a student tried to kill his mother with a hammer and injured his sister. He mentioned later that the French "amok-killer" was his model.

14th of March 1996 in Dunblane, Great Britan: a man rushed into the gymnasium of an elementary school with four weapons and shot around him. 17 persons were killed. 4 months later: in Wolverhampton, Great Britain, a 32 year old man injured 7 persons with a machete in a kindergarten. It was found that he had collected reports of the Dunblane incident.

23th of April 1999: 2 students killed 13 persons in a school. 30 days later: a 15-year old student shot in the morning in his school, 6 injured.

31.07.1999: A daytrader shot in the office of a stockbroker, also in an other bureau. 06.08.1999. A man fired into his previous office and killed his boss and 2 other persons.

07.03.2001: Amok event in the Santana High School in California. A boy shot and smiled. 09.03.2001: Shootings in a school in Pennsylvania. A girl fired into a cafeteria.

Also the hypotheses was tested whether the events in which the killer also committed suicide were further more followed by murder/ suicide events. The results showed that murder suicide cases $(28 \%)$ were not more often followed by murder-suicide cases than by other cases. Murder-suicide cases were followed by murder-suicide cases in $53 \%$ of all cases, murder-no suicide cases were followed by murder-no suicide cases in $38 \%$ of all cases (Chi-square $=0,89$, ns.).

\section{DISCUSSION}

One result of our study shows that as in other fields in psychiatry the public opinion based on media coverage of events often does not reflect reality. Despite the great media coverage, the number of original amok events has been significantly decreasing over the last years.

The time series of the events shows some irregularities. The majority of events are not 
distributed by chance over time. There-fore, as in the studies of imitation of suicides the hypothesis seems to gain plausibility that also amok events may be imitated. Most amok events follow an other event in a period of time which is within the frame given by many studies of imitation: 10 days in Phillips studies (1974; Phillips, Lesyna \& Paight, 1992), 18 days in the study by Schmidtke and Hăfner (1988). This uneven distribution speaks for a possible imitation effect.

The similarities with regard to the persons or the acts themselves are more difficult to prove. There are examples of strong similarities between the events as already shown by Cantor \& Sheehan (1996) and there are also strong similarities in many cases with regard to the modus operandi of the acts.

In the present study amok persons are mainly younger males, these results are similar to those found in previous studies which examined cases or files (Adler 2001). To a high degree they are having problems in partnership. Their motives are often described as revenge motives. Not mentioned in previous studies, surprisingly high is the rate of people with a connection to professions where guns are used or at least familiar: soldiers and policemen. This percentage is much higher than the rate of these protessions in the population and than one would expect by chance. As in the studies of police suicides (Schmidtke et al., 1999) it seems that the easy access to special methods may also facilitate amok behaviour.

The only person variables so far which speak for a similarity between model and imitator is the same sex and main age. However one has to bear in mind, that the majority of all amok killers belong to this age and sex group (Adler 2001).

However, there are examples of a strong similarity between the acts as already shown by Cantor and Sheehan (1996). Therefore, one has to test the similarities of the modus operandi in further studies.

As the study already shows - as the studies for suicidal behaviour show-it may be dangerous to report about amok events in a sensational way. The reporting may trigger the same attitude and behaviour in persons who found themselves in a similar state of mood.

That it would be possible to use the media also for preventing such acts is clearly shown by some studies.

The study by Sonneck and coworkers shows preventive effects of mass media. Since its opening in 1978 , the Vienna subway system has been used as a way to attempting or committing suicide. The number was very low in early years, but beginning in 1984, suicides and suicide attempts increased. This trend was neither due to an extension of the Viennese subway system nor to an increase in the number of passengers. However, the major Austrian newspapers reported these suicides in a very sensational and dramatic way. Therefore, the Austrian Association for Suicide Prevention created media guidelines and requested the press to follow them beginning in June 1987. After these guidelines were published, the general quality of reporting changed markedly. Instead of printing sensational articles, the papers printed either short reports, rarely on the front page, or did not report suicides at all. At the same time, the number of suicides in the 
subway significantly decreased from the first to the second half of 1987 , and the rates remained low as this figure shows. A similar effort was made in Switzerland. In the context of the Swiss national suicide prevention program also the Swiss Association for Suicide Prevention tried to persuade the press not to report about suicides in a sensational way. The results showed also a decrease in suicide rates.

It was also hypothesized that the special media coverage portraying the suicide of the singer, Kurt Cobain, as an unreasonable act and a useless way of problem solving (especially published in the interview with his widow) prevented copycat suicides (Kienhorst, 1994; Berman, Jobes \& O'Carroll, 1995, Jobes et al., 1996; Berman et al., 1997).

Therefore, this striking relation between the change in the style of reporting by the print media and the number of suicides supports the hypothesis that reports and portrayals of suicidal and perhaps amok behaviour, especially in a certain manner, may trigger additional suicides and amok events; vice versa toning down press reports may have a preventive effect.

In Germany there was a similar case which illustrates the danger of this kind of press reporting: recently a man killed his girlfriend who left him and two of her daughters, the motive was revenge for being rejected. The event was covered by the media in a very sensational way. One day later an other man also killed the daughter of his former girlfriend to hurt her.

During the study the Anthrax cases in the US happened. In the last months one could also see that the extensive reporting about the Anthrax cases obviously triggered people to imitate these acts not only in the US but also in other countries of the world.

\section{REFERENCES}

Adler L (2001). Amok im Spektrum homizidalsuizidaler Handlungen. Suicidprophylaxe, 28, 103108.

Adler L (2000). Amok. München: Belleville.

Adler L, Lehmann K, Räder K, Schünemann KF (1993). "Amokläufer" -kontentanalytische Untersuchung an 196 Pressemitteilungen aus industrialisierten Lăndern. Fortschritte der Neurologie und Psychiatrie, 61, 424-433.

Arboleda-Florez J (1971). Amok. In: RC Simon \& CC Hughes (Eds.) The culture bound syndromes. Dordrecht: Reidel, 251-262.

Bach-y-Rita G, Lion JR, Climent CE, Ervin FR (1971). Episodic dyscontrol -a study of 130 violent patients. American Journal of Psychiatry, 127, 4957.

Berkowitz L, Macaulay J (1971). The contagion of criminal violence. Sociometry, 34, 238-260.

Berman A, Jobes D, O'Carroll P (1995). The aftermath of Kurt Cobains's suicide. Paper presented at the XVIII Congress of the International Association for Suicide Prevention, Venice.

Cantor CH, Sheehan PW (1996). Violence and media reports -a connection with Hungerford? Archives of Suicide Research, 2, 255-266.

Etzersdorfer $E$ (2001). Suicide prevention by the media: Austrian experience. Paper presented at the Con-gress NoSuicide, Geneva. 
Etzersdorfer E, Sonneck G (1999). Suizjdprāvention durch Beeinflussung von Medienberichten. Psychotherapie, 4, 199-205.

Gould MS, Shaffer D (1986). The impact of suicide in television movies. New England Journal of Medicine, 315, 690-694.

Hawton K, Simkin S, Deeks JJ, O'Connor S, Keen A, Altman DG, Philo G, Bulstrode C (1999). Effects of a drug overdose in a television drama on presentations to hospital for self poisoning: time series and questionnaire study. British Medical Journal, 318, 972.977.

Häfner H, Schmidtke A (1986). Effects of the mass media on suicidal behaviour and deliberate self-harm. WHO-Paper ICP/PSF 017/10.

Jobes DA, Berman AL, O'Carrol P, Eastgard S, Knickmeyer $S$ (1996). The Kurt Cobain suicide crisis: perspectives from research, public health and the news media. Sucide and Life Threatening Behavior, $26,260-271$.

Kienhorst I (1994). Kurt Cobain. Crisis, 15: 6263.

Kraepelin E (1904). Vergleichende Psychiatrie. Zentralbl. Gesamte Neurol. Psychiat. 27, 433- 437.

Maletzky B M (1973). The epsisodic dyscontrol syndrome. Diseases of the Nervous System, 34, 178185.

Murphy H B M (1982). The affective disorders of comparative psychiatry. The international and intercultural distribution of mental illness. In: Murphy, H. B. M. (Eds.) Berlin: Springer, 108-114.

Oxford English Dictionary. 1989. Oxford: Clarendon, 407.

Phillips DP (1974). The influence of suggestion on suicide: Substantive and theoretical implications of the Werther effect. American Sociological Review, $39,340-354$.

Phillips DP (1982). The impact of fictional television stories on U.S. adult fatalities: New evidence on the effect of the mass media on violence. American Journal of Sociology, 87: 1340-1359.

Phillips DP (1983). The impact of mass media violence on U.S. homicides. American Sociological Review, 48: 560-568.

Phillips DP (1998). The Werther effect. Suicide, and other forms of violence, are contagious. Sciences, 25, 32-39.

Phillips DP, Carstensen LL (1998.) The effect of suicide stories on various demographic groups, 196885. Suicide and Life-Threatening Behavior, 18, 100 114.

Phillips DP, Carstensen LL (1996). Clustering of teenage suicides after television news stories about suicide. New England Joumal of Medicine, 315, 685689.

Phillips DP, Hensley JE (1984). When violence is rewarded or punished: The impact of mass media stories on homicide. Journal of Communication, 34, 101-116.

Phillips DP, Lesyna MA, Paight DJ (1992). Suicide and the media. In: RW Maris, AL Berman, JT Maltsberger and Rl Yufit (Eds.). Assessment and Prediction of Suicide. New York: Guilford.

Schmidtke A, Fricke S, Lester D (1999). Suicide among German Federal and State police officers. Psychological Reports, 84, 157-166.

Schmidtke A, Hāfner H (1988). The Werther effect after television films-evidence for an old hypothesis. Psychological Medicine, 18, 665-676.

Schmidtke A, Schaller $S(2000)$. The role of mass media in suicide prevention. In: $\mathrm{K}$ Hawton \& $K$ van Heeringen (Eds.). International handbook of suicide and attempted suicide. New York: Wiley, 675 697.

Schmidtke A, Schaller S (1998). What do we know about media effects on imitation of suicidal behavior? State of the art. In: D Deleo, DA Schmidtke \& RFW Diekstra (Eds.) Suicide prevention - A holistic approach. Kluwer, 121-137. 


\begin{tabular}{lllll}
$K$ & $R$ & 1 & $Z$ \\
\hline
\end{tabular}

Schmidtke A, Schaller S, Wasserman D (2001). Suicide clusters and media coverage of suicide. In Wasserman $D$ (Ed.). Suicide -An unnecessary death. London: Dunitz, 265-268.

Sjegel S (1956). Nonparametric statistics. London. MacGraw Hill.

Stack S (1989). The effect of publicezed mass murders and murder suicides on lethal violence, 1968-1980: A research note. Social
Psychiatriy and Psychiatric Epidemiology, 1989, 24, 202-208.

Stack S (1996). The effect of the media on suicide: evidence from Japan. Suicide and LifeThreatening Behavior, 26, 405-414.

Velting DM, Gould MS (1997). Suicide contagion. In: RW Maris, MS Silverman \& SS Canetto (Eds.) Review of Suicidology. New York: Guilford, 96137. 